\title{
A Promising Orange-Red Nanocrystalline Potassium Lanthanum Orthophosphate for White Light-Emitting Diodes
}

\author{
Palvi Gupta, ${ }^{1}$ A. K. Bedyal, ${ }^{1}$ Vinay Kumar, ${ }^{1,2}$ Y. Khajuria, ${ }^{1}$ \\ O. M. Ntwaeaborwa, ${ }^{2}$ and H. C. Swart ${ }^{2}$ \\ ${ }^{1}$ School of Physics, Shri Mata Vaishno Devi University, Katra 182320, India \\ ${ }^{2}$ Department of Physics, University of the Free State, P.O. Box 339, Bloemfontein 9300, South Africa \\ Correspondence should be addressed to Vinay Kumar; vinaykumar@smvdu.ac.in
}

Received 23 November 2013; Accepted 15 January 2014; Published 19 February 2014

Academic Editors: S. Ghosh, F. Gourbilleau, and M. Razeghi

Copyright (C) 2014 Palvi Gupta et al. This is an open access article distributed under the Creative Commons Attribution License, which permits unrestricted use, distribution, and reproduction in any medium, provided the original work is properly cited.

The spectral properties of the $\mathrm{K}_{3} \mathrm{La}\left(\mathrm{PO}_{4}\right)_{2}$ :Eu ${ }^{3+}$ nanophosphors synthesized by the combustion method are reported. The phosphors were characterized by X-ray diffraction, transmission electron microscopy, and optical spectroscopy. The XRD pattern reveals a pure monoclinic phase of the $\mathrm{K}_{3} \mathrm{La}\left(\mathrm{PO}_{4}\right)_{2}$ with the average particle size of $30 \mathrm{~nm}$ in diameter. Under UV excitation, the phosphors exhibited several emission bands which were assigned to $4 \mathrm{f}-4 \mathrm{f}$ transitions of $\mathrm{Eu}^{3+}$ ions. The red shade of the $\mathrm{Eu}^{3+}$ ion with the CIE coordinates $(x, y)$ as $(0.63,0.37)$ suggests that this material is a promising phosphor for near-UV InGaN-based LED lighting.

\section{Introduction}

In recent years, white light-emitting diodes (LEDs) have attracted more attention as possible replacement of the incandescent and fluorescent light sources due to their extraordinary characteristics such as high luminous efficiency, low cost synthesis, energy saving, long lifetime, reliability, mercury free, and environmental friendliness [1-4]. The rare earth doped phosphates are an important family of luminescent materials for solid state lighting applications as they possess excellent properties such as large band gap, moderate phonon energy, high thermal and chemical stability, exceptional optical damage threshold, and high absorption of $\mathrm{PO}_{4}{ }^{3-}$ in the VUV region [5-7]. Among the phosphates families, orthophosphate is considered to be an excellent host material to accommodate large amount of dopants due to its large band gap. Very often, orthophosphate crystallizes in the monoclinic phase with space group $\mathrm{Pc} / \mathrm{m}$ or $\mathrm{Pc} / \mathrm{n}$ [8].

The electronic transitions in the inner $4 \mathrm{f}$ orbitals, which are not influenced by the $5 \mathrm{~s}$ and $5 \mathrm{p}$ electrons, are only found in the lanthanide. This leads to narrow and intense emission bands which are useful sources of the individual colors in multiphosphor devices. Therefore, in many commercial phosphors the blue $(450 \mathrm{~nm})$, green $(545 \mathrm{~nm})$, and red $(610 \mathrm{~nm})$ emissions of $\mathrm{Eu}^{2+}, \mathrm{Tb}^{3+}$, and $\mathrm{Eu}^{3+}$ have been widely used $[9,10]$. Currently, there are several techniques used to synthesize these materials, like colloidal [11, 12], sonochemical [13], spray pyrolysis [14], and high temperature solid-state reactions $[15,16]$.

In the present paper, we report on the structure and photoluminescence (PL) properties of $\mathrm{Eu}^{3+}$ activated $\mathrm{K}_{3} \mathrm{La}\left(\mathrm{PO}_{4}\right)_{2}$ nanophosphors synthesized by the combustion technique.

\section{Experimental}

$\mathrm{K}_{3} \mathrm{La}\left(\mathrm{PO}_{4}\right)_{2}: \mathrm{Eu}^{3+}(2 \mathrm{~mol} \%)$ phosphors were synthesized via the combustion method using urea as a fuel. All the chemicals used in the preparation were of analytical grade and were used without further purification. The starting materials were potassium nitrate $\left(\mathrm{KNO}_{3} \cdot 4 \mathrm{H}_{2} \mathrm{O}\right)$, lanthanum (III) nitrate hexahydrate $\left(\mathrm{La}\left(\mathrm{NO}_{3}\right)_{3} \cdot 6 \mathrm{H}_{2} \mathrm{O}\right)$, ammonium dihydrogen tetraoxophosphate $(\mathrm{V})\left(\mathrm{NH}_{4} \mathrm{H}_{2} \mathrm{PO}_{4}\right)$, urea $\left(\mathrm{NH}_{2} \mathrm{CONH}_{2}\right)$, and europium nitrate $\left(\mathrm{Eu}\left(\mathrm{NO}_{3}\right)_{3} \cdot 6 \mathrm{H}_{2} \mathrm{O}\right)$. The reagents were weighed according to the balanced chemical reaction given below. The ratio of the metal nitrates (oxidizers) and urea (fuel) was calculated using the total oxidizing and reducing valences of the components to get an equivalent 
ratio of unity to enable complete combustion. The ratio of an oxidizer and fuel is expressed as follows:

$$
\phi_{c}=\frac{\sum \text { coff. of oxidising element } \times \text { Valency }}{(-1) \sum \text { coff. of reducing element } \times \text { Valency }} .
$$

In the reaction (3), $\mathrm{KNO}_{3} \cdot 4 \mathrm{H}_{2} \mathrm{O}(-5)$ and $\mathrm{La}\left(\mathrm{NO}_{3}\right)_{3} \cdot 6 \mathrm{H}_{2} \mathrm{O}$ $(-15)$ are oxidizing elements, whereas $\mathrm{NH}_{4} \mathrm{H}_{2} \mathrm{PO}_{4}(+3)$ and $\mathrm{NH}_{2} \mathrm{CONH}_{2}(+6)$ are reducing elements. By using the oxidising and reducing values in (1), we have

$$
\therefore \quad \phi_{c}=\frac{3 \times(-5)+1 \times(-15)}{(-1)[2 \times(+3)+4 \times(+6)]}=1 .
$$

The weighed reactants were dissolved in few drops of distilled water and thoroughly mixed in agate mortar to obtain thick paste. The paste was transferred to alumina crucible and placed in a furnace, preheated to a temperature of $550^{\circ} \mathrm{C}$. The paste underwent volumetric combustion with evolution of large amounts of gasses. The reaction took 3-5 minutes to be completed. The final white foamy product was cooled to room temperature and ground to obtain a fine powder. The powder was annealed at $800^{\circ} \mathrm{C}$ for $2 \mathrm{~h}$ to improve the crystallinity and also to remove reactants which could not be decomposed at lower temperature. Consider

$$
\begin{aligned}
& 3 \mathrm{KNO}_{3} \cdot 4 \mathrm{H}_{2} \mathrm{O}+(1-x) \mathrm{La}\left(\mathrm{NO}_{3}\right)_{3} \cdot 6 \mathrm{H}_{2} \mathrm{O} \\
& +2 \mathrm{NH}_{4} \mathrm{H}_{2} \mathrm{PO}_{4}+4 \mathrm{NH}_{2} \mathrm{CONH}_{2}+x \mathrm{Eu}\left(\mathrm{NO}_{3}\right)_{3} \\
& \cdot 6 \mathrm{H}_{2} \mathrm{O} \longrightarrow \mathrm{K}_{3} \mathrm{La}_{1-x} \mathrm{Eu}_{x}\left(\mathrm{PO}_{4}\right)_{2}+\text { gaseous product }
\end{aligned}
$$

The structure of the product was examined by using a Bruker Advance $\mathrm{D} 8 \mathrm{X}$-ray diffractometer with $\mathrm{Cu}, \mathrm{K} \alpha$ irradiation $(\lambda=1.5406 \AA)$. Transmission electron microscopy (TEM) was used to examine the particle size and morphology of the phosphor. The TEM images were taken with a JEM-2100 at an accelerating voltage of $200 \mathrm{kV}$. The emission and excitation spectra (PL) of the phosphors were recorded by using a CaryEclipse spectrofluorometer.

\section{Results and Discussion}

Figure 1 shows the X-ray diffraction (XRD) pattern of the annealed $\mathrm{K}_{3} \mathrm{La}\left(\mathrm{PO}_{4}\right)_{2}: \mathrm{Eu}^{3+}$ nanophosphor. The characteristic reflections confirm the monoclinic phase of the $\mathrm{K}_{3} \mathrm{La}\left(\mathrm{PO}_{4}\right)_{2}$ orthophosphates. The crystal structure of the host matrix was not affected by the addition of small amount of $\mathrm{Eu}^{3+}$ dopant

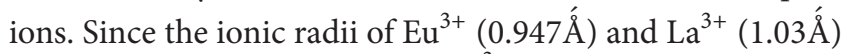
are approximately the same, the $\mathrm{Eu}^{3+}$ ions can therefore easily incorporate in $\mathrm{La}^{3+}$ sites in host lattice. The XRD pattern was compared with those of the standard JCPDS data (47-0468) and the peaks were indexed accordingly. The diffraction peaks at $23.7^{\circ}, 28.5^{\circ}$, and $25.5^{\circ}$ (in terms of $2 \theta$ ) indicate that some impurity phases were present in the host. The average crystallite size calculated by the well-known Debye-Scherrer equation [17] was $30 \mathrm{~nm}$.

The morphology of the $\mathrm{K}_{3} \mathrm{La}\left(\mathrm{PO}_{4}\right)_{2}$ : $\mathrm{Eu}^{3+}$ nanophosphors was analyzed using TEM as shown in Figure 2. From the

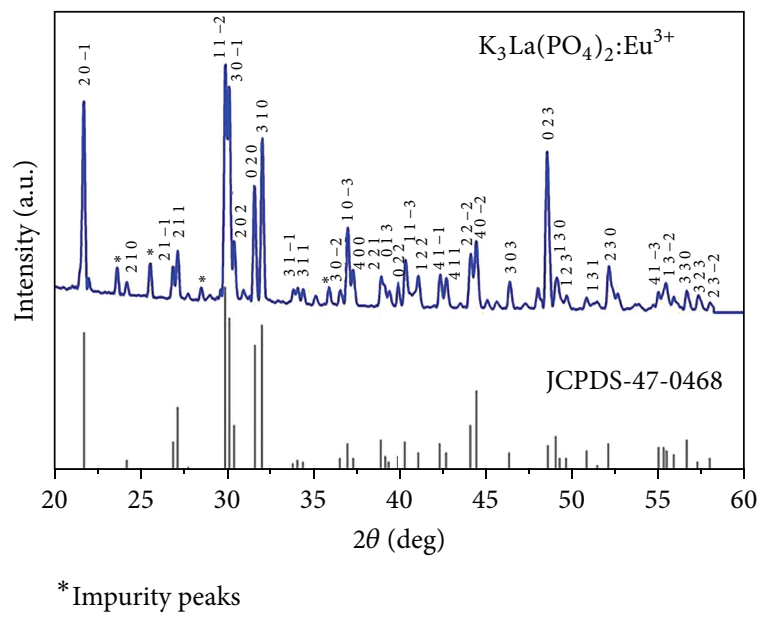

FIGURE 1: XRD pattern of the $\mathrm{K}_{3} \mathrm{La}\left(\mathrm{PO}_{4}\right)_{2}: \mathrm{Eu}^{3+}$ nanophosphors.

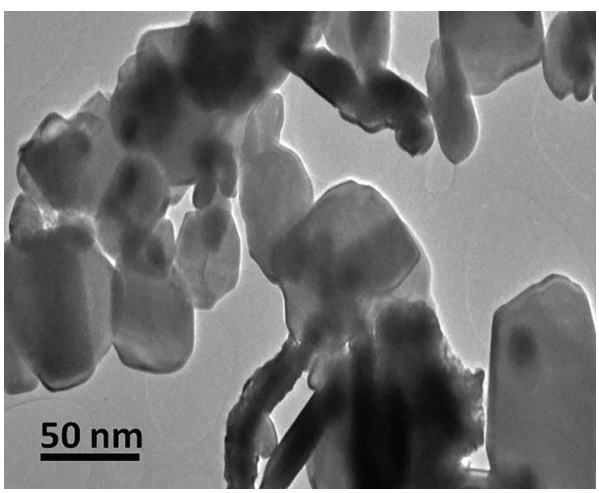

FIGURE 2: TEM image of the $\mathrm{K}_{3} \mathrm{La}\left(\mathrm{PO}_{4}\right)_{2}: \mathrm{Eu}^{3+}$ nanophosphors.

micrograph, the particles were mostly spheroidal and the average particle size was estimated to be in the range of $\sim 28 \pm 2 \mathrm{~nm}$. This result is consistent with the XRD data. It is well known that the morphological characteristics of the combustion derived products are strongly dependent on the heat and gas generated during the reaction. Large amounts of gases generated during the combustion process are suitable for preparation of fine particles, while the heat released is an important factor for crystal growth. This type of porous network is typically the characteristic of combustion synthesized powders. The porous powders are highly friable which facilitates easy grinding to obtain finer particles. The evolution of gas with high pressure leads to the formation of pores along with the simultaneous growth of small particles near the pores [16].

Figure 3 shows the photoluminescence excitation spectrum of the $\mathrm{K}_{3} \mathrm{La}\left(\mathrm{PO}_{4}\right)_{2}: \mathrm{Eu}^{3+}$ phosphor. The spectrum has a broad band ranging from 200 to $310 \mathrm{~nm}$ with a set of sharp lines protruding from the band. The broad band is attributed to charge transfer (CTB) from $\mathrm{O}^{2-} \rightarrow \mathrm{Eu}^{3+}$, while the sharp lines at wavelengths of 318, 360, 382, and $392 \mathrm{~nm}$ are assigned to $\left({ }^{7} \mathrm{~F}_{0} \rightarrow{ }^{5} \mathrm{H}_{3},{ }^{5} \mathrm{D}_{4},{ }^{5} \mathrm{G}_{j},{ }^{5} \mathrm{~L}_{7},{ }^{5} \mathrm{~L}_{6}\right)$ intraconfigurational $4 \mathrm{f}-4 \mathrm{f}$ transitions of $\mathrm{Eu}^{3+}$ ion. 


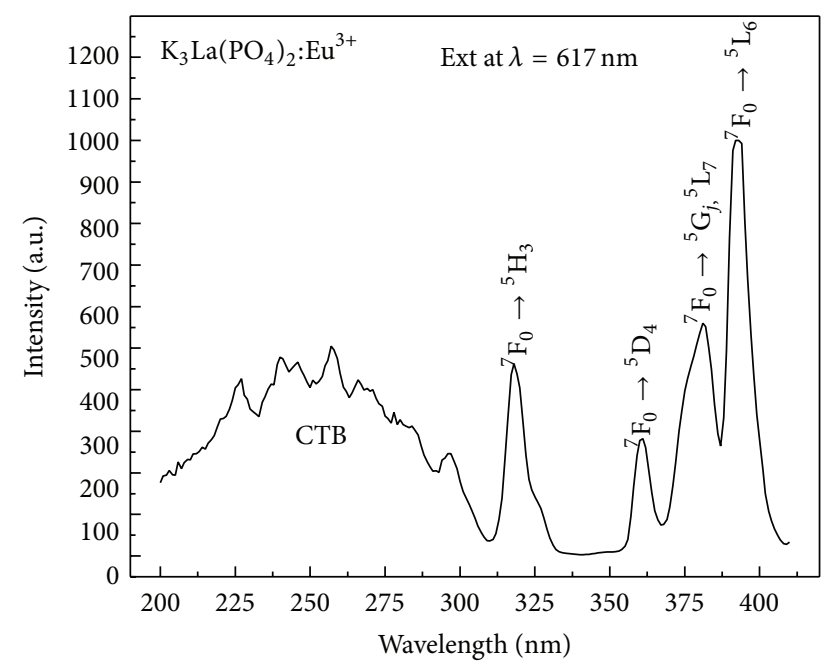

Figure 3: PL excitation spectrum of the $\mathrm{K}_{3} \mathrm{La}\left(\mathrm{PO}_{4}\right)_{2}: \mathrm{Eu}^{3+}$ nanophosphors.

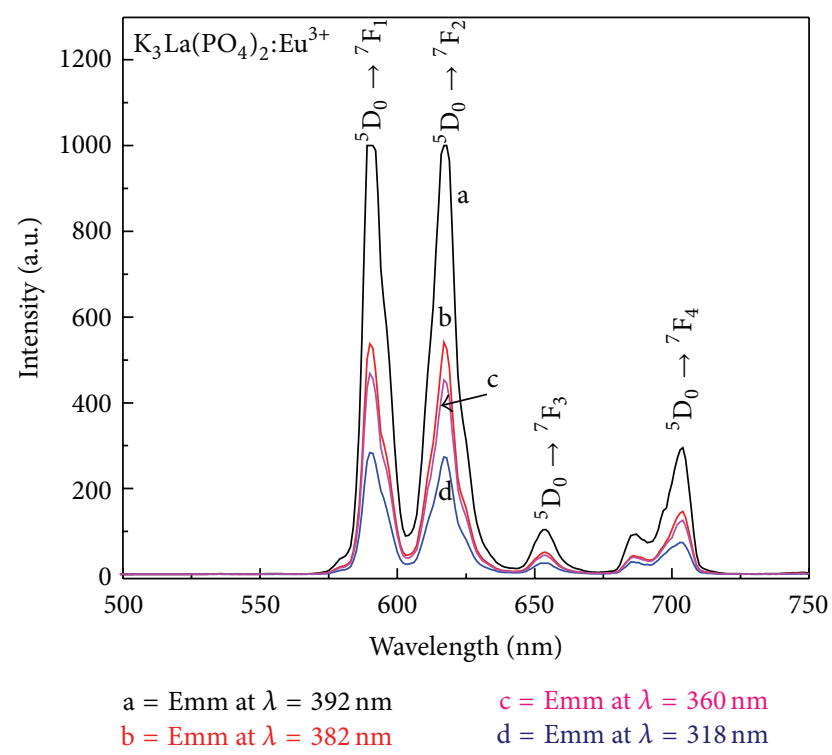

Figure 4: PL emission spectra of the $\mathrm{K}_{3} \mathrm{La}\left(\mathrm{PO}_{4}\right)_{2}: \mathrm{Eu}^{3+}$ nanophosphors.

The PL emission spectra at different excitation wavelengths are presented in Figure 4 and it is clear that the peak positions and shapes of the spectra did not change for all the excitation wavelengths. The emission spectrum consists of four typical emission peaks at 591, 617, 653, and $703 \mathrm{~nm}$, which results from the intraconfigurational $4 \mathrm{f}-4 \mathrm{f}$ characteristic transitions $\left({ }^{5} \mathrm{D}_{0} \rightarrow{ }^{7} \mathrm{~F}_{j}, j=1,2,3,4\right)$ of the $\mathrm{Eu}^{3+}$ ion, respectively. The emission line at $591 \mathrm{~nm}$ is due to magnetic dipole transition ${ }^{5} \mathrm{D}_{0} \rightarrow{ }^{7} \mathrm{~F}_{1}$ which is insensitive to the site symmetry, whereas the emission at $617 \mathrm{~nm}$ is due to the electric dipole transition of ${ }^{5} \mathrm{D}_{0} \rightarrow{ }^{7} \mathrm{~F}_{2}$ and it is induced by the lack of inversion symmetry at the $\mathrm{Eu}^{3+}$ site. Generally, the forced electric dipole transitions arise from the lack of centre of symmetry and it is much stronger than

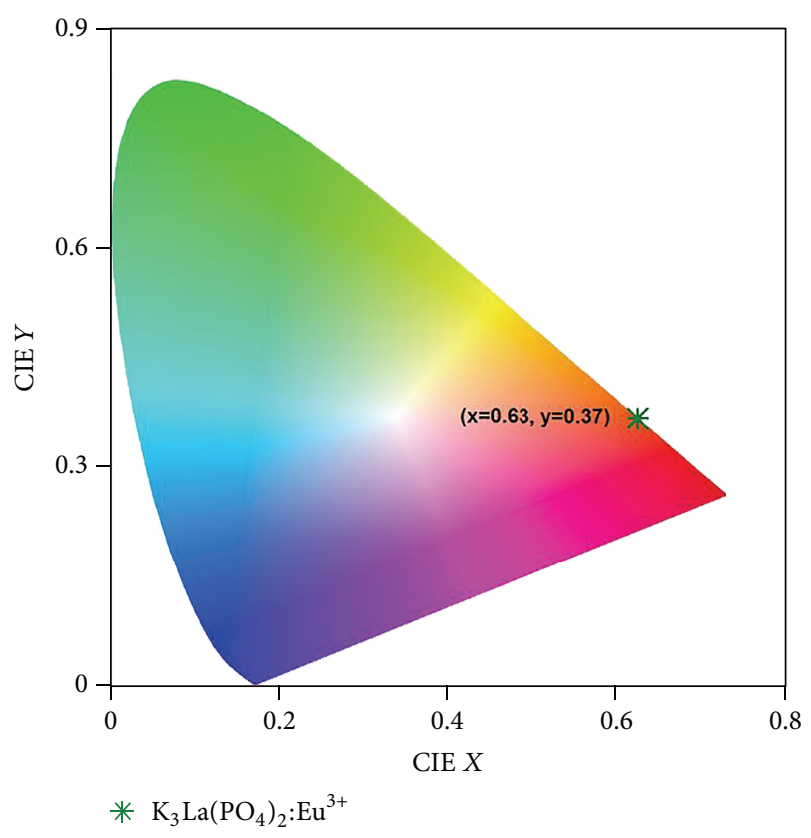

FIgurE 5: The CIE 1931 chromaticity diagram for $\mathrm{K}_{3} \mathrm{La}\left(\mathrm{PO}_{4}\right)_{2}: \mathrm{Eu}^{3+}$ nanophosphors under $392 \mathrm{~nm}$ excitation.

that of the ${ }^{5} \mathrm{D}_{0} \rightarrow{ }^{7} \mathrm{~F}_{1}$ transition. Also, the ${ }^{5} \mathrm{D}_{0} \rightarrow{ }^{7} \mathrm{~F}_{2}$ transition is dependent upon the local symmetry, while the ${ }^{5} \mathrm{D}_{0} \rightarrow{ }^{7} \mathrm{~F}_{1}$ emission is related to the local symmetry due to insensitivity to the site symmetry. Therefore, in the present case, the $\mathrm{Eu}^{3+}$ ion occupies a symmetric and a nonsymmetric site almost equally, as both the peak intensities of $\mathrm{Eu}^{3+}$ ion due to ${ }^{5} \mathrm{D}_{0} \rightarrow{ }^{7} \mathrm{~F}_{2}$ and ${ }^{5} \mathrm{D}_{0} \rightarrow{ }^{7} \mathrm{~F}_{1}$ transitions are the same $[18,19]$. The CIE 1931 color space chromaticity coordinates were calculated and are presented in the CIE diagram in Figure 5. The diagram was constructed using the Commission International de L'Eclairage (CIE) coordinate calculator. The calculated CIE coordinates of our materials were $(0.63,0.37)$ which correspond to the shade of orange-red emission of the $\mathrm{Eu}^{3+}$ ion. Bright orange-red lightemitting diodes may be fabricated by the combination of the synthesized $\mathrm{K}_{3} \mathrm{La}\left(\mathrm{PO}_{4}\right)_{2}: \mathrm{Eu}^{3+}$ with $392 \mathrm{~nm}$ emitting InGaNbased chips.

\section{Conclusions}

$\mathrm{K}_{3} \mathrm{La}\left(\mathrm{PO}_{4}\right)_{2}: \mathrm{Eu}^{3+}$ nanophosphors were synthesized by the combustion method and its luminescence properties were investigated under UV excitation. The emission spectrum consists of two prominent peaks at 591 and $617 \mathrm{~nm}$ which corresponds to magnetic-dipole transitions $\left({ }^{5} \mathrm{D}_{0} \rightarrow{ }^{7} \mathrm{~F}_{1}\right)$ and electric-dipole transitions $\left({ }^{5} \mathrm{D}_{0} \rightarrow{ }^{7} \mathrm{~F}_{2}\right)$ of the $\mathrm{Eu}^{3+}$ ion. The CIE chromaticity coordinates were calculated to be $(x=0.63, y=0.37)$ which corresponds to the orangered shade. The maximum emission from $392 \mathrm{~nm}$ excitation makes this material a potential candidate for the near-UVlight-emitting diode applications. 


\section{Conflict of Interests}

The authors declare that there is no conflict of interests regarding the publication of this paper.

\section{Acknowledgments}

A. K. Bedyal would like to thank Inter University Accelerator Centre, New Delhi, for the financial support in the form of fellowship under UFR Project code-MS/30505. Vinay Kumar is grateful to the Department of Science and Technology (DST), Government of India, for funding the Fast Track Project reference no. SR/FTP/PS-043/2011 under DST Young Scientist Scheme.

\section{References}

[1] S. Pimputkar, J. S. Speck, S. P. Denbaars, and S. Nakamura, "Prospects for LED lighting," Nature Photonics, vol. 3, no. 4, pp. 180-182, 2009.

[2] S. Ye, F. Xiao, Y. X. Pan, Y. Y. Ma, and Q. Y. Zhang, "Phosphors in phosphor-converted white light-emitting diodes: recent advances in materials, techniques and properties," Materials Science and Engineering R, vol. 71, no. 1, pp. 1-34, 2010.

[3] T. Murata, T. Tanoue, M. Iwasaki, K. Morinaga, and T. Hase, "Fluorescence properties of $\mathrm{Mn}^{4+}$ in $\mathrm{CaAl}_{12} \mathrm{O}_{19}$ compounds as red-emitting phosphor for white LED," Journal of Luminescence, vol. 114, no. 3-4, pp. 207-212, 2005.

[4] P. F. Smet, K. Korthout, J. E. Van Haecke, and D. Poelman, "Using rare earth doped thiosilicate phosphors in white light emitting LEDs: towards low colour temperature and high colour rendering," Materials Science and Engineering B, vol. 146, no. 13, pp. 264-268, 2008.

[5] M. J. J. Lammers, H. C. G. Verhaar, and G. Blasse, "Lumine scence of $\mathrm{Ce}^{3+}$ and $\mathrm{Tb}^{3+}$ in $\mathrm{M}_{3}\left(\mathrm{PO}_{4}\right)_{2}(M=S r, \mathrm{Ba})$," Materials Chemistry and Physics, vol. 16, no. 1, pp. 63-66, 1987.

[6] S. H. M. Poort, W. Janssen, and G. Blasse, "Optical properties of $\mathrm{Eu}^{2+}$-activated orthosilicates and orthophosphates," Journal of Alloys and Compounds, vol. 260, no. 1-2, pp. 93-97, 1997.

[7] E. N. Silva, A. P. Ayala, I. Guedes et al., "Vibrational spectra of monazite-type rare-earth orthophosphates," Optical Materials, vol. 29, no. 2-3, pp. 224-230, 2006.

[8] W. Jungowska and T. Znamierowska, "The system $\mathrm{LaPO}_{4}$ $\mathrm{K}_{3} \mathrm{PO}_{4}$," Journal of Solid State Chemistry, vol. 95, no. 2, pp. 265269, 1991.

[9] C. Feldmann, T. Jüstel, C. R. Ronda, and P. J. Schmidt, "Inorganic luminescent materials: 100 years of research and application," Advanced Functional Materials, vol. 13, no. 7, pp. 511-516, 2003.

[10] T. Jüstel, H. Nikol, and C. Ronda, "New developments in the field of luminescent materials for lighting and displays," Angewandte Chemie, vol. 37, pp. 3084-3103, 1998.

[11] V. Buissette, M. Moreau, T. Gacoin, J.-P. Boilot, J.-Y. ChaneChing, and T. Le Mercier, "Colloidal synthesis of luminescent rhabdophane $\mathrm{LaPO}_{4}: \mathrm{Ln}^{3+} \cdot \mathrm{xH}_{2} \mathrm{O}(\mathrm{Ln}=\mathrm{Ce}, \mathrm{Tb}, \mathrm{Eu} ; \mathrm{x} \approx 0.7)$ nanocrystals," Chemistry of Materials, vol. 16, no. 19, pp. 37673773, 2004.

[12] K. Riwotzki, H. Meyssamy, A. Kornowski, and M. Haase, "Liquid-Phase synthesis of doped nanoparticles: colloids of luminescing $\mathrm{LaPO}_{4}: \mathrm{Eu}$ and $\mathrm{CePO}_{4}$ :Tb particles with a narrow particle size distribution," Journal of Physical Chemistry B, vol. 104, no. 13, pp. 2824-2828, 2000.

[13] S. S. Brown, H.-J. Im, A. J. Rondinone, and S. Dai, "Facile, alternative synthesis of lanthanum phosphate nanocrystals by ultrasonication," Journal of Colloid and Interface Science, vol. 292, no. 1, pp. 127-132, 2005.

[14] I. Wuled Lenggoro, B. Xia, H. Mizushima, K. Okuyama, and N. Kijima, "Synthesis of $\mathrm{LaPO}_{4}$ :Ce,Tb phosphor particles by spray pyrolysis," Materials Letters, vol. 50, no. 2-3, pp. 92-96, 2001.

[15] D. C. Tuan, R. Olazcuaga, F. Guillen, A. Garcia, B. Moine, and C. Fouassier, "Luminescent properties of $\mathrm{Eu}^{3+}$-doped yttrium or gadolinium phosphates," Journal de Physique IV, vol. 123, pp. 259-263, 2005.

[16] O. A. Serra and R. M. Campos, "Síntese e propriedades luminescentes de fosfatos de európio (III)," Quimica Nova, vol. 14, pp. 159-161, 1991.

[17] B. D. Cullity, Element of X-Ray Diffraction, Addison-Wesley, New York, NY, USA, 2nd edition, 1956.

[18] X. C. Zhou, L. P. Zhong, Q. P. Liu, R. Y. Kuang, and H. M. Chen, "Luminescence properties of Bi codoped and $\mathrm{P}$ codoped $\mathrm{Ca}_{3}\left(\mathrm{VO}_{4}\right)_{2}: \mathrm{Eu}^{3+}$," Inorganic Materials, vol. 45, no. 11, pp. 1295$1298,2009$.

[19] S. Lu and J. Zhang, "Study on UV excitation properties of Eu ${ }^{3+}$ doped rare-earth phosphates," Journal of Luminescence, vol. 122123, no. 1-2, pp. 500-502, 2007. 

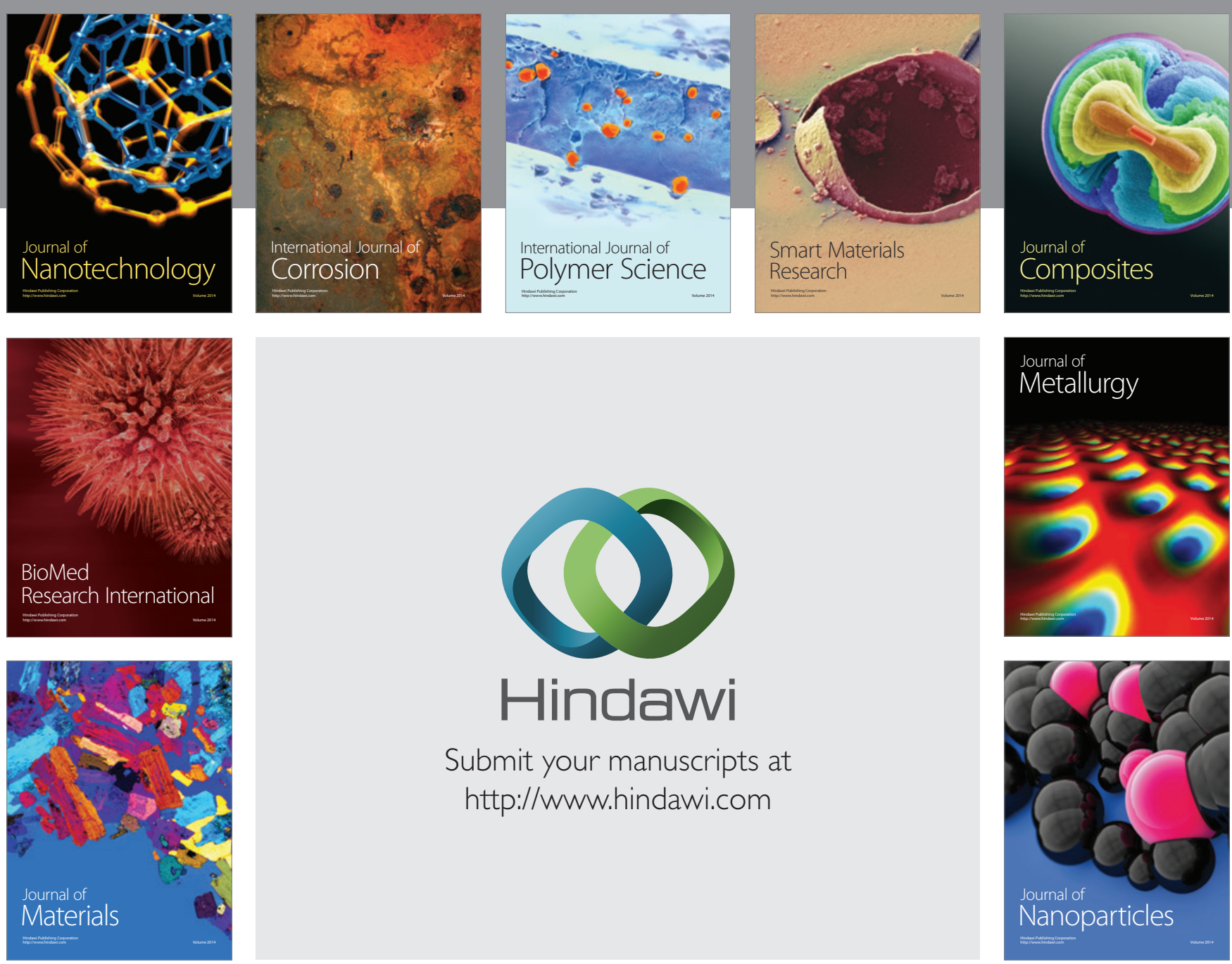

Submit your manuscripts at http://www.hindawi.com
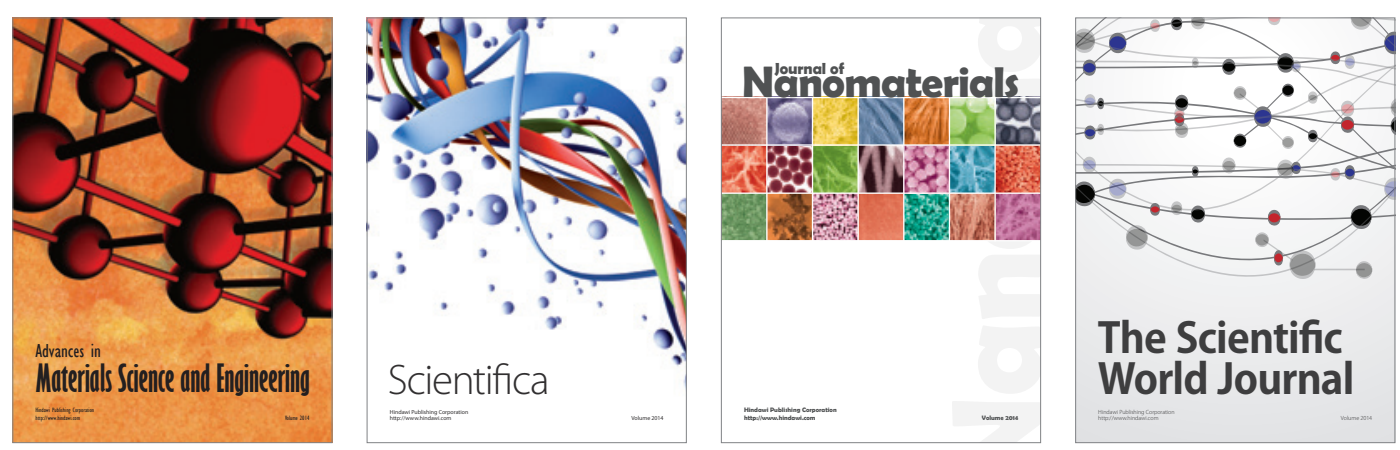

\section{The Scientific World Journal}
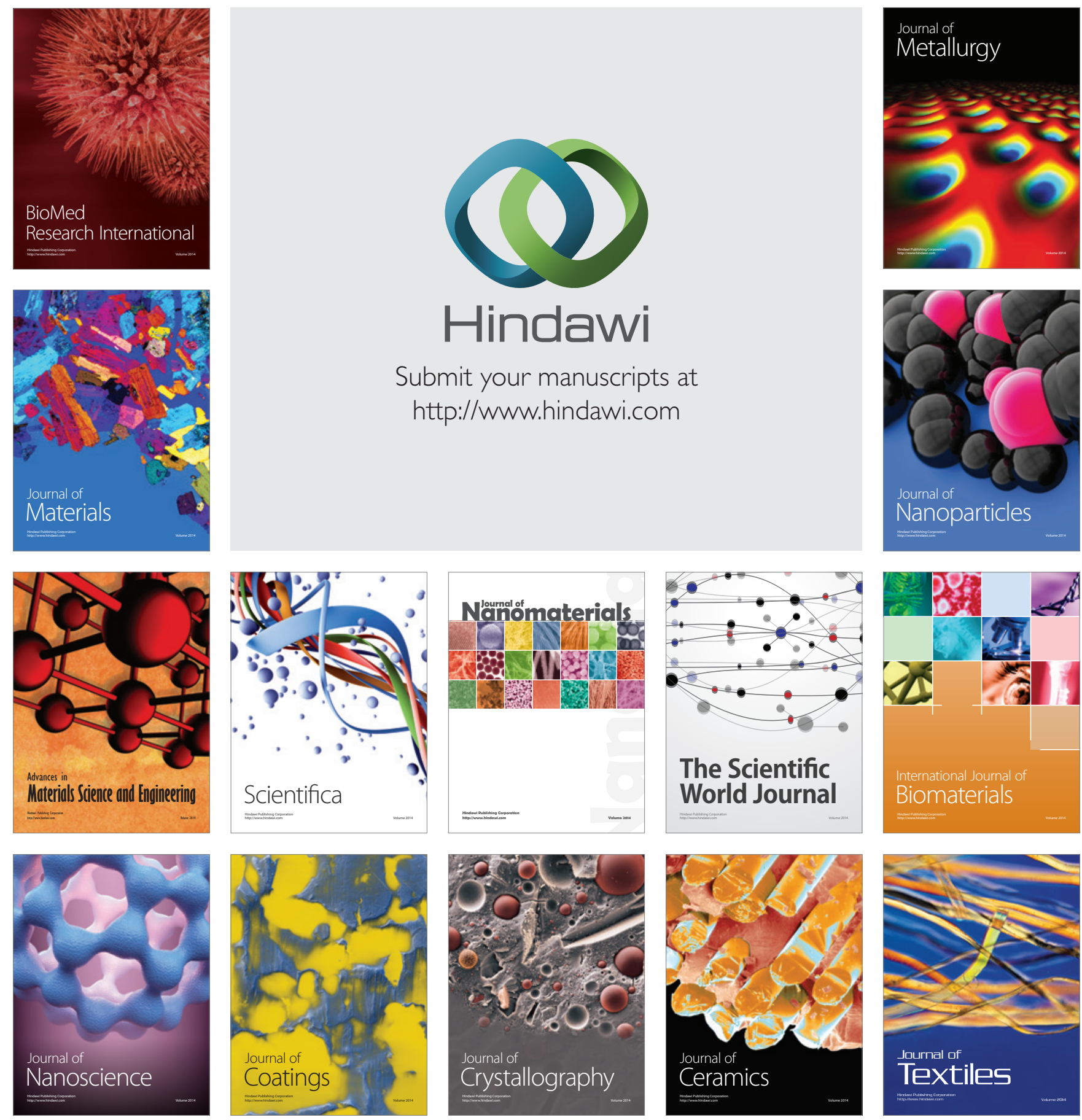